\title{
Mumps epidemiology in Germany 2007-11
}

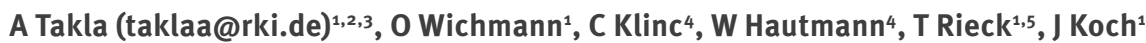

1. Immunization Unit, Robert Koch Institute, Berlin, Germany

2. Postgraduate Training for Applied Epidemiology (PAE), Berlin, Germany

3. European Programme for Intervention Epidemiology Training (EPIET), Stockholm, Sweden

4. Bavarian Health and Food Safety Authority (LGL), Oberschleißheim, Germany

5. Charité - University Medical Center, Berlin, Germany

Citation style for this article:

Takla A, Wichmann O, Klinc C, Hautmann W, Rieck T, Koch J. Mumps epidemiology in Germany 2007-11. Euro Surveill. 2013;18(33):pii=20557. Available online: http://www.eurosurveillance.org/ViewArticle.aspx?Articleld=20557

Article submitted on 22 January 2013 / published on 15 August 2013

In Germany, mumps has been notifiable until 2013 only in the five Eastern federal states (EFS) of former East Germany. Due to different immunisation policies until 1990 and varying vaccination coverages thereafter, mumps incidences cannot be extrapolated to the 11 Western federal states (WFS). We studied mumpsrelated International Classification of Diseases (ICD10) code diagnoses claimed through statutory health insurances between 2007 and 2011 to estimate countrywide mumps incidences in the outpatient sector, and compared them with case numbers from ambulatory notification data. Overall, 32,330 outpatient mumps cases were claimed. Annual incidence ranged between $9.3 / 100,000$ and 11.8/100,000 and showed a significant decreasing trend. Compared with EFS, mumps incidence in WFS was higher and indicated a shift towards older age groups. Notified outpatient case numbers in EFS were 13-fold lower and from voluntary surveillance during an outbreak in the WFS Bavaria 8-fold lower than from insurance data $(n=316$ versus $n=4,217$ and $n=238$ versus 1,995, respectively). Of all notified cases with available information, $75.4 \%$ (EFS) and $57.6 \%$ (Bavaria) were unvaccinated; $6.8 \%$ (EFS) and $19.3 \%$ (Bavaria) required hospitalisation. In Germany, mumps is still endemic despite decades of vaccination, with considerable underreporting in the established notification systems.

\section{Introduction}

Mumps is a vaccine-preventable viral disease, typically characterised by swelling of the parotid glands, but can also cause severe complications like orchitis, meningitis, encephalitis or pancreatitis $[1,2]$. The disease usually occurs among children and in the prevaccine era, the annual reported mumps incidences in Western European countries ranged between 100 and 600 per 100,000 inhabitants [3]. With the availability of a live-attenuated mumps vaccine since the $1960 \mathrm{~s}$ [4], disease incidence dramatically decreased in countries with mumps vaccination programmes $[5,6]$. Over the past years, however, numerous reports from different countries with long-established vaccination programmes have been published about extensive mumps outbreaks that occurred predominantly among vaccinated children, adolescents, and young adults [7-15].

Until 2013, mumps has been notifiable in Germany only in the five Eastern federal states (EFS) of former East Germany. During the years 2001 to 2011, annually reported incidence for all EFS ranged between 0.26 and $0.78 / 100,000$ [16]. There was no mandatory notification system in place in the remaining 11 Western federal states (WFS) of former West Germany. However, if an outbreak occurs in an institutional setting, the 'German Infection Protection Act' requires the institution to immediately inform the district health authority. A recent comprehensive survey suggested an increase in the number of mumps outbreaks over the past 10 years [17]. The largest recorded outbreak occurred in the WFS of Bavaria in 2010/11. Voluntary (ad-hoc) reporting was set up during the outbreak period and identified 295 cases.

Although mumps incidences have been available for EFS for the past 10 years, incidences cannot be extrapolated to the 11 WFS due to historical differences in vaccination schedules and coverage rates. While West Germany had recommended one dose of mumps vaccine as part of the routine childhood vaccination schedule from 1976 onwards, East Germany had no mumps vaccination programme in place until reunification in 1990. Since 1991, two doses (in the second and sixth year of life) have been recommended throughout the reunified Germany, since 2001 with the first dose given at 11-14 months and the second dose at 15-23 months of age [18]; the vaccine strain predominantly used is Jeryl Lynn. Although routine mumps vaccination was adopted in EFS 15 years later than in WFS, vaccination coverage rates at school entry have been substantially higher in EFS since introduction of coverage monitoring in 1998 (Figure 1) [19].

In the absence of a countrywide mandatory mumps notification requirement until March 2013 we used billing data of the Associations of Statutory Health Insurance Physicians (ASHIP) for outpatients as an alternative data source. Approximately $85 \%$ of the 
Mumps vaccination coverage rates for first and second dose at school entry (age 5-7 years) in Western and Eastern federal states, Germany, 1998-2010

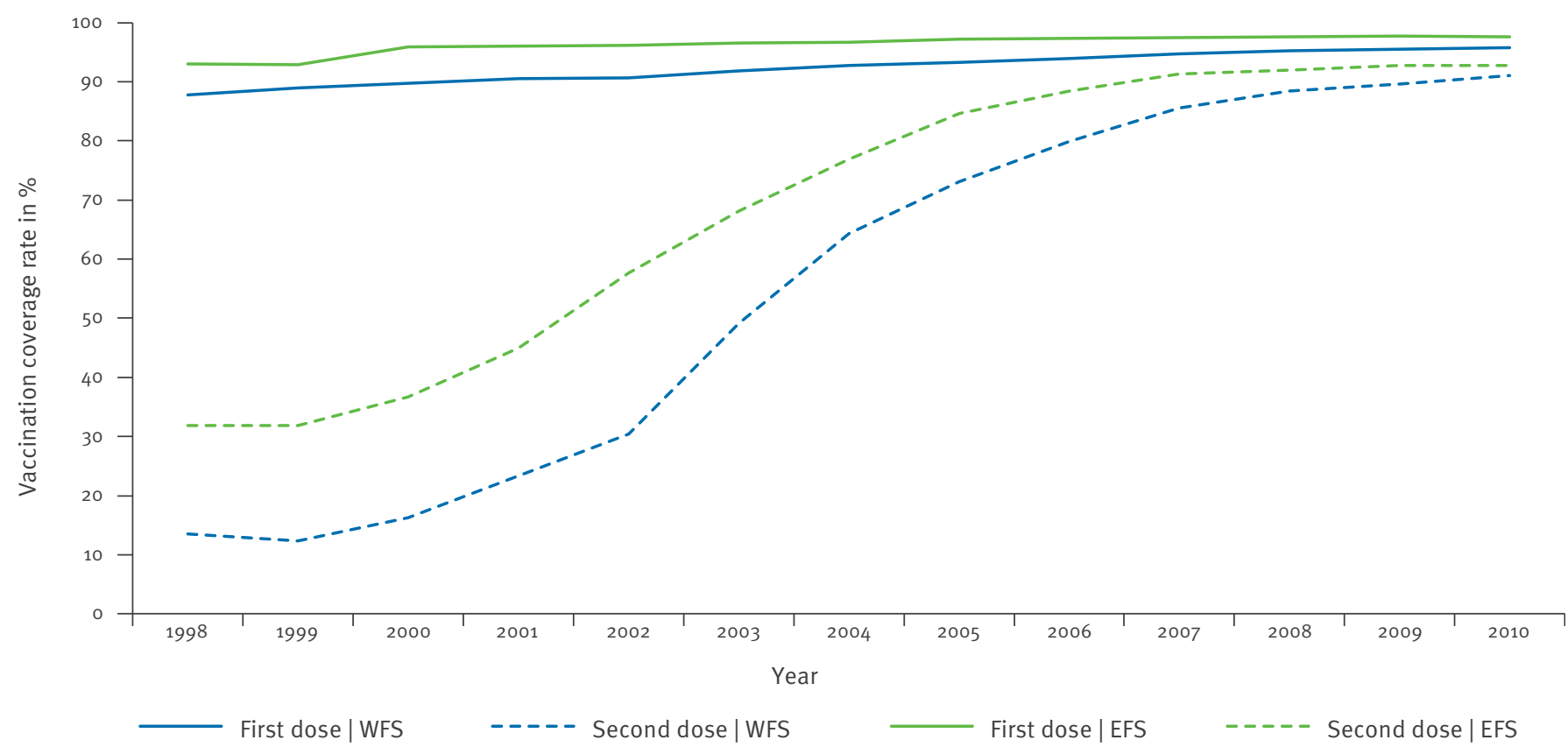

EFS: Eastern federal states; WFS: Western federal states.

population living in Germany is covered by statutory health insurances (total population in Germany in 2011: 81.8 million; WFS: 69.0 million, EFS: 12.8 million), and mumps is a disease usually treated on an outpatient basis (in EFS 2001-11: 94\%). The aim of our study was to use countrywide ASHIP data (i) to estimate ambulatory mumps incidences and describe mumps-related demographics countrywide and separately for EFS and WFS, (ii) to estimate incidence and describe demographics for the outbreak in Bavaria 2010/11, and (iii) to compare the number of cases and demographics identified in the ambulatory ASHIP dataset with corresponding figures from the mandatory notification system in EFS and ad-hoc notification during the 2010/11 outbreak in Bavaria.

\section{Methods}

\section{Definitions}

For ASHIP data, a mumps case was defined as a person diagnosed with a mumps-related International Classification of Diseases (ICD-10) code (B26.0orchitis, B26.1-meningitis, B26.2-encephalitis, B26.3pancreatitis, B26.8-'other complication', B26.9-'no complication'), and for notification data as a person fulfilling the mumps case definition (clinical case, i.e. more than two days of one- or two-sided parotidal swelling without any other apparent cause, and/or clinical case with epidemiological link and/or clinical case with laboratory confirmation) [20]. Incidence based on
ASHIP data was defined as number of outpatient cases per 100,000 statutory health-insured [21], whereas incidence based on the mandatory notification system was defined as number of outpatient cases per 100,000 inhabitants in Germany [22]. The German federal states of Brandenburg, Mecklenburg-Western Pomerania, Saxony, Saxony-Anhalt, and Thuringia were classified as EFS; Baden-Württemberg, Bavaria, Berlin (comprising of the former Eastern and Western part of the city), Bremen, Hamburg, Hesse, Lower Saxony, North Rhine-Westphalia, Rhineland-Palatinate, Saarland, Schleswig-Holstein as WFS. The Bavarian outbreak period ranged from the third quarter of 2010 to the second quarter of 2011, the non-outbreak period were the remaining quarters in the years 2007 to 2011.

ASHIP data structure and data included in the analysis

Statutory health insurance physicians send their reimbursement claims for provided ambulatory medical services, based on the ICD-10 code, to their corresponding regional ASHIP on a quarterly basis. Our dataset included the patient's anonymous unique identifier (ID), sex, month/year of birth, district/state of residence, state of billing physician's practice, ICD10 code, quarter/year of diagnosis, reliability of diagnosis (suspected, confirmed, excluded or recovered), and type of diagnosis (current state, previous state, unknown or not provided). 
Our analysis contained mumps diagnoses billed between 1 January 2007 and 31 December 2011. Data from the states of Baden-Württemberg (2007 only) and Hesse (2007-11) had to be excluded due to incomplete information. After the exclusion, the data set covered $79 \%$ of the population living in Germany during 2008 to 2011 and $68 \%$ during 2007.

\section{ASHIP data cleaning}

We only included confirmed diagnoses that were labelled as 'current state' for the calculation of incidences. To limit the dataset to a single diagnosis per unique ID, we used the following algorithm:

1. Exclusion of incompatible or implausible coding combinations of 'reliability of diagnosis' (e.g. all four options coded in the same quarter);

2. Exclusion of observations coded as suspected, excluded or recovered ('reliability of diagnosis');

3. Exclusion of observations coded as previous state, unknown or not provided ('type of diagnosis');

4. Limitation to the most severe ICD-10 code diagnosed at the earliest point in time (one observation per unique ID), using the following ranking (from most to least severe): encephalitis $>$ meningitis orchitis>p ancreatitis $>$ ther complication $>$ no complication.

For data from Bavaria, Rhineland-Palatinate (2007-11) and regional parts of North Rhine-Westphalia (200811), step 3 had to be omitted as the transmitted data did not routinely contain information on 'type of diagnosis'.

\section{Mandatory and ad-hoc notification data}

We retrieved mandatory mumps notification data reported from EFS through the German electronic surveillance system 'SurvNet' [23] that is routinely used by public health authorities to anonymously report information on inpatient and outpatient cases with notifiable diseases to the national level. The 'SurvNet' system was also used by district health authorities for the voluntary ad-hoc mumps reporting during the outbreak in Bavaria 2010/11. Notification datasets contained information on age, sex, date of disease onset, notification week, district/state of residence, vaccination status, and whether the case required hospitalisation.

\section{Statistical analysis}

We used chi-square test to test differences in incidences and proportions and Poisson regression to determine trends in incidence rate ratios (IRR). $P$ values were defined as statistically significant if $<0.05$. Statistical analysis was performed by using Stata version 12.1 (StataCorp, Texas, US).

\section{Results}

\section{Cleaning of ASHIP data}

A total of 137,087 mumps diagnoses were billed during 2007 to 2011 (Bavaria, Rhineland-Palatinate and parts of North Rhine-Westphalia: 47,165; remaining included states: 89,922$)$. In data cleaning step 1 , the number of diagnoses decreased to $136,142(46,728$ and 89,414$)$, in step 2 to $49,746(16,516$ and 33,230$)$, and in step 3 to $40,819(16,516$ (not applicable) and 24,303$)$. Step 4 limited the dataset to 32,330 confirmed mumps cases (11,330 and 21,000). Among the 86,396 diagnoses excluded in step 2, 36,957 (42.8\%) observations were coded as suspected diagnoses that would, if included in the dataset, have accounted for an additional 29,514 suspected mumps cases after steps 3 and 4 (10,406 and 19,108).

\section{Estimation of countrywide and regional incidences based on ASHIP data}

Of the 32,330 confirmed cases, 15,000 (46.4\%) were male; for 212 (0.7\%) no sex was specified. For the years 2007 to 2011, overall countrywide mumps incidence was $10.3 / 100,000$ and ranged between 9.3/100,000 in 2010 and $11.8 / 100,000$ in 2008 , corresponding to an IRR of 0.95 (95\% confidence interval $(\mathrm{Cl})$ : 0.95-0.96; p<0.005). The most affected age groups in 2007 to 2011 were children aged five to nine years (mean annual incidence: $20.7 / 100,000$ ) and adolescents aged 15 to 19 years $(17.9 / 100,000)$. The most common complication was orchitis ( $n=933 ; 6.2 \%$ of male cases), followed by 'other complication' $(n=581 ; 1.8 \%)$, meningitis $(n=141$; $0.4 \%)$, pancreatitis $(n=92 ; 0.3 \%)$, and encephalitis $(n=61 ; 0.2 \%)$. Except for orchitis, proportions of complications showed no statistically significant difference between sexes. The proportion of complications among cases 15 years and older was significantly higher for all entities than among cases younger than 15 years (orchitis: $7.9 \%$ versus $1.8 \%$ among male cases; 'other complication': $1.9 \%$ versus $1.3 \%$; meningitis: $0.5 \%$ versus $0.2 \%$; pancreatitis: $0.3 \%$ versus $0.1 \%$; encephalitis: $0.2 \%$ versus $0.0 \%$; $<<0.005$ for all).

Mean annual mumps incidence in 2007 to 2011 was significantly higher in WFS than in EFS (10.9/100,000 versus 7.5/100,000; p<0.005). Incidences ranged between 7.0 and $8.4 / 100,000$ in EFS, with a significant declining trend over the five years under observation $(I R R=0.95$; 95\% Cl: 0.93-0.97; p<0.005), and between 9.8 and 12.6/100,000 in WFS (IRR=0.96; 95\% Cl: 0.95-0.96; p 0.005$)$. Stratification by age group showed a significant decreasing trend for incidences in the under 20 year-olds in EFS. In the WFS, incidences significantly decreased in the age groups of under 20 year-olds and of those aged 40 years and older, but significantly increased in the 20 to 29 year-olds (Table). The mean annual incidence of orchitis was higher in WFS than in EFS (0.72/100,000 versus $0.12 / 100,000$ male cases; p<0.005). The proportion of orchitis complications among male cases by age group and geographic region is displayed in Figure 2.

\section{Description of the 2010/11 outbreak in Bavaria based on ASHIP data}

Between 2007 and 2011, Bavarian physicians billed 6,111 confirmed outpatient mumps cases to the 


\section{TABLE}

Annual mumps incidence, incidence rate ratio and $\mathrm{p}$ value, by age group, based on ambulatory statutory health insurance claims data, Germany, 2007-2011 ( $\mathrm{n}=32,330)$

\begin{tabular}{|c|c|c|c|c|c|c|c|c|}
\hline $\begin{array}{l}\text { Age group } \\
\text { (years) }\end{array}$ & 2007 & 2008 & 2009 & 2010 & 2011 & IRR & $95 \% \mathrm{Cl}$ & $p$ value \\
\hline \multicolumn{9}{|c|}{ Western federal states } \\
\hline$\ll 10$ & 22.7 & 23.3 & 16.8 & 15.4 & 14.7 & 0.87 & $0.86-0.90$ & $<0.005$ \\
\hline $10-19$ & $19 \cdot 3$ & 20.7 & 15.2 & $15 \cdot 3$ & 18.4 & 0.96 & $0.94-0.98$ & $<0.005$ \\
\hline $20-29$ & 12.6 & 16.8 & 12.3 & 16.0 & 17.2 & 1.06 & $1.03-1.08$ & $<0.005$ \\
\hline $30-39$ & 9.9 & 11.9 & 9.8 & 9.4 & 11.0 & 1.00 & $0.97-1.02$ & 0.707 \\
\hline $40-49$ & 8.8 & $9 \cdot 7$ & 8.4 & 7.1 & 8.3 & 0.96 & $0.93-0.98$ & $<0.005$ \\
\hline$\geq 50$ & 8.3 & 7.9 & $7 \cdot 5$ & 6.4 & 6.6 & 0.93 & $0.92-0.95$ & $<0.005$ \\
\hline \multicolumn{9}{|c|}{ Eastern federal states } \\
\hline$<10$ & 19.4 & 17.1 & 13.6 & 13.0 & 9.9 & 0.85 & $0.81-0.90$ & $<0.005$ \\
\hline $10-19$ & 15.9 & 18.1 & 12.5 & 11.4 & 10.1 & 0.88 & $0.83-0.93$ & $<0.005$ \\
\hline $20-29$ & 9.1 & 9.7 & 8.6 & 7.4 & 8.7 & 0.96 & $0.91-1.02$ & 0.208 \\
\hline $30-39$ & 6.6 & 9.2 & 7.7 & 7.5 & 8.3 & 1.02 & $0.96-1.09$ & 0.486 \\
\hline $40-49$ & 7.0 & 7.7 & 6.6 & 6.9 & 7.5 & 1.00 & $0.95-1.06$ & 0.867 \\
\hline$\geq 50$ & 5.5 & 5.2 & $4 \cdot 9$ & 5.2 & 5.2 & 0.99 & $0.95-1.03$ & 0.527 \\
\hline
\end{tabular}

$\mathrm{Cl}$ : confidence interval; IRR: incidence rate ratios.

Significant IRR, $95 \% \mathrm{Cl}$ and $\mathrm{p}$ values are shown in bold.

\section{FIGURE 2}

Mean annual mumps incidence among males and proportion of mumps-associated orchitis among all male mumps cases per age group, based on ambulatory statutory health insurance claims data, Germany 2007-2011

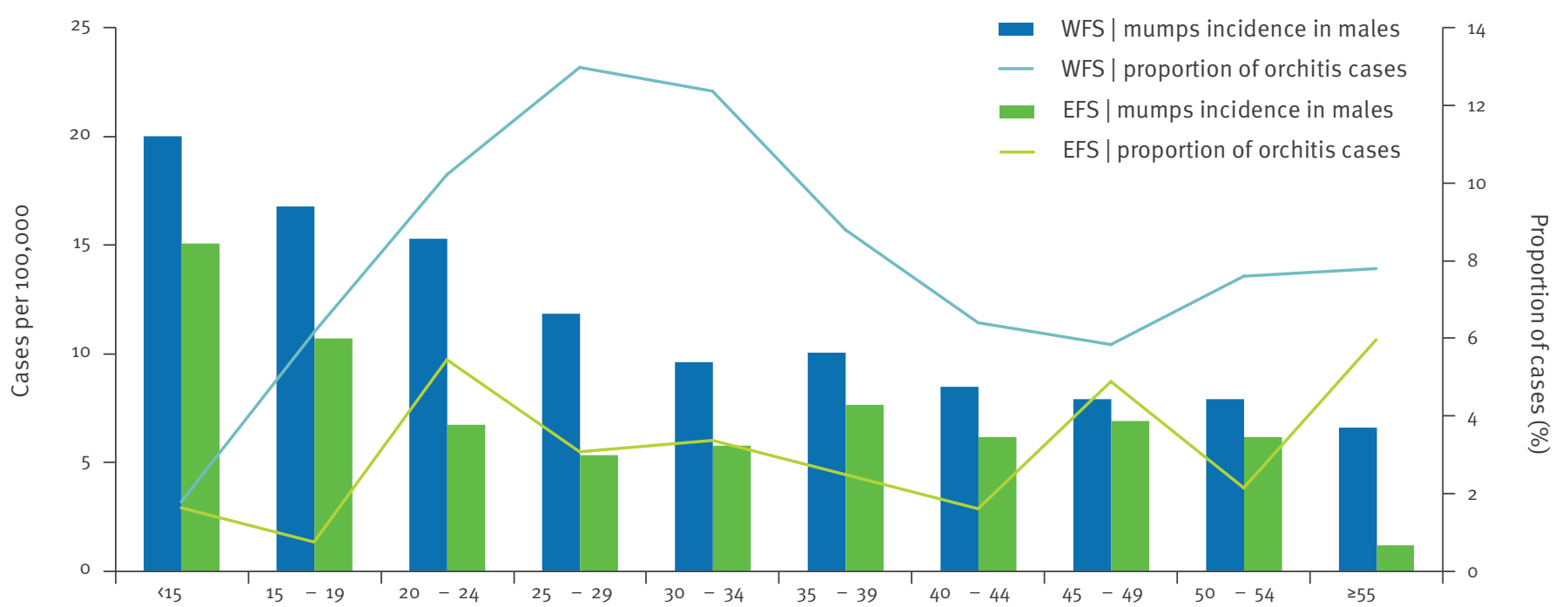

Age group (years)

EFS: Eastern federal states; WFS: Western federal states.

Point estimates for incidences showed $95 \%$ confidence intervals spanning a range of less than 0.05 (not shown in figure). 
Title: Mumps incidence per age group based on ambulatory statutory health insurance claims data during the 2010/11 outbreak period $(n=1,995)$ and non-outbreak period $(n=4,116)$, Bavaria, 2007-2011

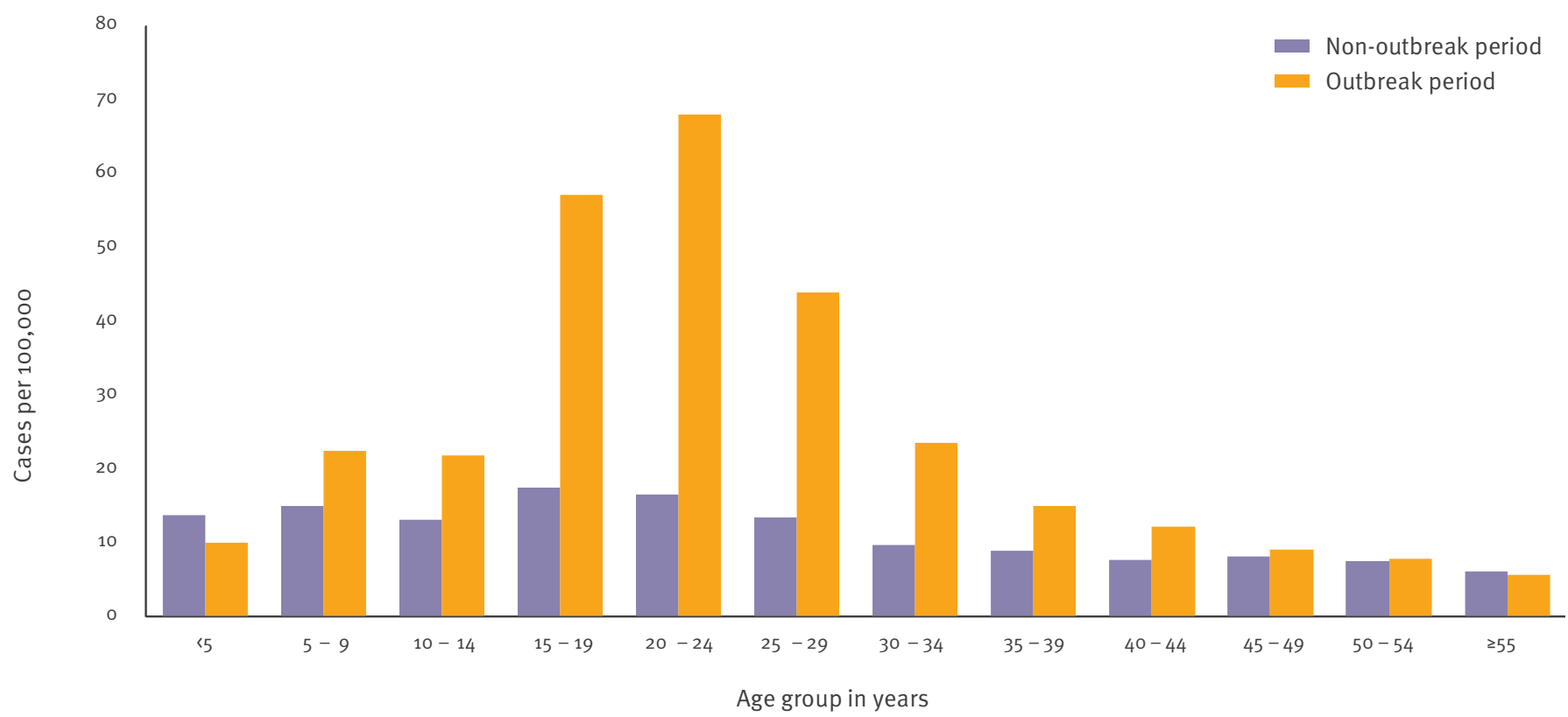

Point estimates showed $95 \%$ confidence intervals spanning a range of less than 0.05 (not shown in figure).

statutory health insurances. Of those, 1,995 (32.6\%) were claimed during the outbreak period with the peak occurring in the first quarter of 2011 ( $n=752 ; 37.7 \%)$. The proportion of claimed male cases was higher during the outbreak period than in the non-outbreak period ( $52.0 \%$ versus $47.5 \%$; p 0.005 ), and a comparison of age-specific incidences indicated that the outbreak affected mainly the age group of 15-34 year-olds (Figure 3). Furthermore, the proportion of orchitis complications was significantly higher during the outbreak period compared to the non-outbreak period $(17.7 \%$ versus $11.7 \%$; p 0.005$)$; all other proportions of complications showed no significant differences (data not shown).

\section{EFS: Comparison of ASHIP data with} mandatory notification data

In EFS, physicians claimed 4,217 confirmed outpatient mumps cases during 2007 to 2011 through the statutory health insurances. The median age of claimed cases was 38 years, and 1,825 (43.3\%) were male. In the same time period, 316 ambulatory and 23 cases that required hospitalisation were reported via the mandatory notification system. The median age of the reported 316 outpatient cases was 12 years, and 148 (46.8\%) were male. In total, 13.3 times more insurance cases were claimed than reported via the mandatory notification system. Stratified by age, 3,048 claimed ambulatory cases were adults ( $\geq 20$ years) compared to 113 notified ambulatory cases (27.0-fold difference); among persons younger than 20 years, the difference was 5.8 -fold ( 1,169 claimed versus 203 notified cases).
Vaccination status was available for 284 (83.8\%) of the 339 cases from the notification system: 214 (75.4\%) were unvaccinated, whereas $70(24.6 \%)$ had received at least one vaccination (33 received one dose, 36 received two doses, and one received four doses). Vaccination status by age group is shown in Figure 4.

\section{Bavarian outbreak 2010/11: Comparison of} ASHIP data with ad-hoc notification data Temporary voluntary notification during the mumps outbreak in Bavaria identified 238 ambulatory cases and 57 cases requiring hospitalisation. Of the ambulatory cases, 124 (52.1\%) were male. The median age was 21 years versus 24 years in ASHIP data. In comparison to ASHIP data $(n=1,995)$, there was an 8.3fold difference to ad-hoc reporting. Stratified by age, 107 reported ambulatory cases were younger than 20 years, compared with 594 outpatient cases claimed in insurance data (a 5.6-fold difference); in the group 20 years and older, 131 cases were reported, in contrast to 1,401 cases from ASHIP data (a 10.7-fold difference). Vaccination status was available for 217 of 295 (73.6\%) reported cases: 125 (57.6\%) were unvaccinated and $92(42.4 \%)$ had received at least one vaccination (38 received one dose, 53 received two doses and one received three doses); for vaccination status per age group see Figure 5 .

\section{Discussion}

Because countrywide mandatory mumps notification was not in place until 2013, we used mumps-related ICD-10 code diagnoses claimed through statutory 
Vaccination status per age group among mumps cases with known status, reported via the mandatory notification system, Eastern federal states, 2007-2011 $(n=284)$

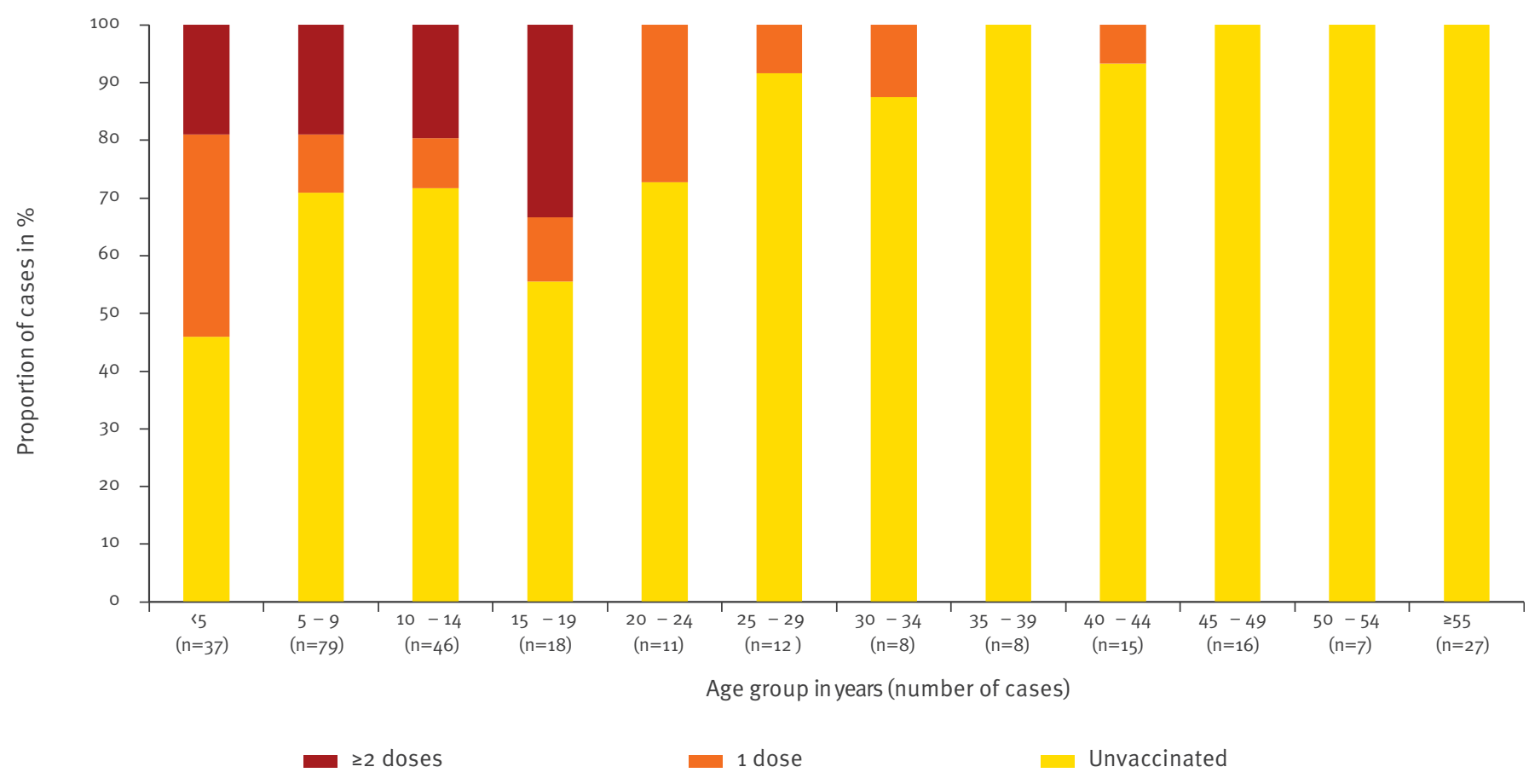

health insurances to estimate the magnitude of mumps incidence in Germany. Our results demonstrate that mumps is still endemic in Germany despite long-established vaccination programmes. However, overall incidences have dramatically declined from an estimated 100 to 1,000 cases per 100,000 in the pre-vaccine era [24] to 10.3 per 100,000 in the time period from 2007 to 2011. Moreover, incidences showed a further slight but statistically significant decreasing trend during the five-year study period, although incidence patterns across age groups differed in WFS and EFS. This discrepancy can be explained by different dates of mumps vaccine introduction and different vaccination coverages in the following years.

In the absence of a mumps vaccination programme in EFS until 1991, a great proportion of the EFSpopulation born before 1990 is likely to have been exposed to the wild virus and to have acquired natural immunity during childhood, consistent with the considerably lower incidences in adults in EFS compared with WFS, especially in the age group of 20 to 29 year-olds. Serosurveys from European countries in the pre-vaccine era have shown that $90 \%$ of the population was seropositive by the age of 14 to 15 years [4]. Because routine mumps vaccination was introduced in the WFS in 1976, high prevalence rates of naturally acquired immunity are only found in those who were born in 1975 and later (in our dataset 32 to 36 years and older). During 1976-90, the WFS recommended one mumps vaccine dose, but comprehensive data on coverage rates from that period are not available. The two-dose mumps recommendation, introduced in WFS and EFS in 1991, has only targeted children born after 1990 (in our dataset 17 to 21 years and younger). The significant incidence differences in individuals younger than 20 years as well as the significant decreasing trend over the study period correspond to increasing vaccination coverages seen at school entry in both EFS and WFS. However, two-dose coverage in EFS has been substantially higher since beginning of monitoring. Although two-dose vaccination coverage rates are approaching levels to reach herd immunity of at least $92 \%$ [25] in both parts of the country, previous lower rates and a lack of catch-up vaccination activities may have left a pool of susceptibles that account for the high incidences in children and young adults. A representative seroprevalence study, conducted in 2003 to 2006 among more than 13,000 individuals aged o to 17 years in Germany, revealed approximately $20-22 \%$ to be mumps IgG-negative or borderline-positive, with higher proportions in the WFS [26]. However, if the present high vaccination coverage at school entry can be sustained, incidences among children can be expected to further decrease.

In contrast to EFS, we observed in WFS a significant increasing incidence trend among 20 to 29 year-olds, suggesting an age-shift over time. This observation is mirrored by the Bavarian outbreak 2010/11 where highest incidences were seen among 15 to 29 year-olds; the finding is further in line with recent outbreak reports from other countries with long-established vaccination programmes $[10-13,15]$. One reason could be that 
Vaccination status per age group among mumps cases with known status, reported via the voluntary ad-hoc notification system, Bavarian outbreak 2010/2011 ( $\mathrm{n}=217)$

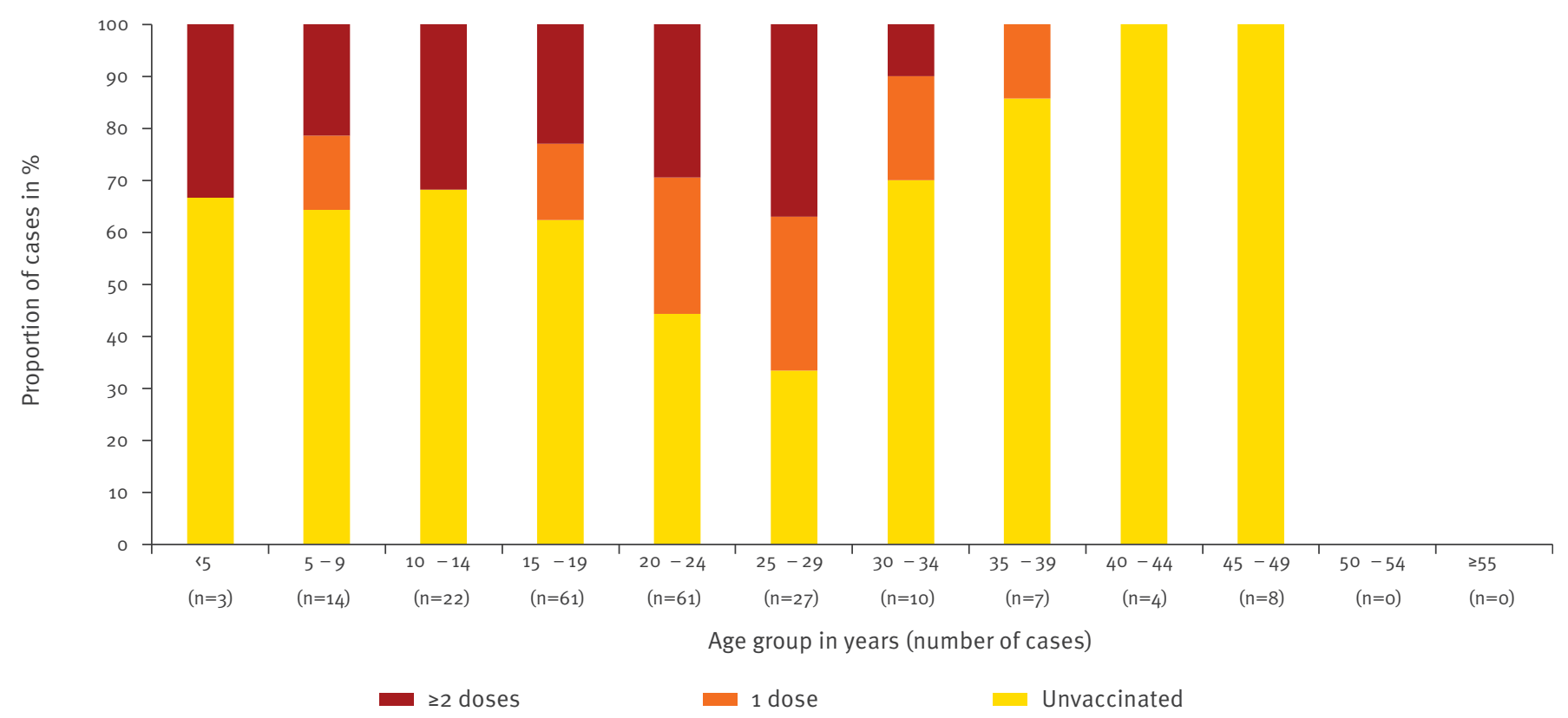

suboptimal vaccination coverage rates combined with low circulation of wild virus have caused an accumulation of susceptibles in those age groups. This theory is supported by the German serosurvey [26], but also by 86,098 immunisation records from 10 to 12 year-olds in Bavaria in 1988 (born one to three years after adoption of mumps vaccination) that revealed mumps coverage rates of only $55 \%$ [27]. Another relevant factor could be waning immunity. In the same serosurvey, authors identified significant waning effects already in 0 to 17 year-old immunised children [26], and those effects could be even more dominant in older age groups with longer time spans since last vaccination and/or only one vaccination dose. Furthermore, the proportion of vaccinated cases in the Bavarian outbreak increased with age in the group of 15 to 29 year-olds. Although we only had vaccination status information for 217 reported cases, age and sex distribution were comparable with findings from ASHIP data. The results could therefore be a hint that waning immunity may indeed play a role in those age groups in Germany. In contrast, breakthrough infections were not observed among young adult cases in EFS; all breakthrough infections occurred among children and adolescents and could therefore reflect the expected proportion of vaccine failure in populations with high vaccination coverage.

Mumps incidences for Germany based on ASHIP data are substantially higher than incidences for Europe published by the European Centre for Disease Prevention and Control: 3.5 per 100,000 in 2010 [28] and 3.2 per 100,000 in 2009 [29]. However, the 27 countries differ in their mumps surveillance systems, case definitions and time points of routine mumps vaccine introduction $[30,31]$, and comparisons are therefore difficult.

Comparison of the mandatory notification data with ASHIP data in EFS indicated severe underreporting, especially among adults. Underreporting could even be higher, as we only included cases coded as confirmed and diagnosed in an ambulatory practice. Our findings suggest that in EFS, where mandatory mumps surveillance has been in place since 1964 [24], physicians diagnose mumps, but fail to report cases to public health authorities. This has important implications as Germany has introduced nationwide mandatory reporting of mumps as of March 2013. To retain reliable mumps notification data, it is crucial not only to (re)inform physicians about their reporting duty, but to think of new strategies to ease reporting. One approach could be to develop computer tools that directly link the ICD coding of notifiable infectious diseases with a report to the health authorities.

There is an increasing use of electronic health records or claims data to estimate disease trends or disease burden, especially for admission or discharge ICD codes from hospitals, e.g. for rotavirus, gonorrhoea, or varicella [32-34]. In Germany, ICD-10 codes have previously been used to assess the herpes zoster disease burden also in the outpatient sector [35], and to assess reporting completeness of notifiable disease surveillance systems [36,37]. However, electronic health records or claims data cannot and should not replace a surveillance system, as the data are usually only available with a time lag of several months, precluding rapid containment actions in the event of an outbreak, and 
are primarily intended for documentation or reimbursement, not surveillance purposes. In the case of ASHIP data, important information such as vaccination status at diagnosis or required hospitalisation is lacking. Nevertheless, such data can be an important source to assess the magnitude of incidences, disease trends and underreporting, and their reliability to determine communicable disease trends and burden should be further explored, also for the outpatient sector.

Using ASHIP data to estimate mumps incidences had several limitations related to data structure. There are no standardised guidelines for physicians of when to code a case as suspected or confirmed. Aiming at a conservative estimate, we decided to only include confirmed diagnoses. This restriction, as well as limiting the dataset to one observation per patient (who may have had several physician consultations during one disease episode), reduced the initial dataset considerably during the cleaning process. Therefore, the extent of the reduction cannot be interpreted as an indicator for the ASHIP data quality per se. As laboratory confirmation is not required to code a case as confirmed, the proportion of laboratory confirmations is unknown. Moreover, ASHIP data only cover ambulatory cases. However, since mumps has a very distinct clinical presentation and the vast majority of mumps patients remain outpatients or have consulted their ambulatory physician before complications may require hospitalisation, it can be assumed that our incidence estimates are a good reflection of the true disease incidence.

Our dataset did not include the ca. $15 \%$ of the population with private health insurance. However, we used the ASHIP population as denominator to calculate incidences and do not expect that mumps vaccination coverage differs substantially between privately and statutory insured. Finally, as information on 'type of diagnosis' is routinely missing for Bavaria, RhinelandPalatinate and parts of North Rhine-Westphalia, we could not exclude diagnoses coded as 'previous state', 'unknown' or 'not provided' in the data cleaning process. However, if proportions of reduction had been applied to these federal states as observed for the others (step 3: $26.9 \%$; step 4: $13.6 \%$ ), the total number of cases would have been reduced by only 899 (2.7\%).

\section{Conclusions}

ASHIP data proved a valuable alternative data source to estimate mumps incidences. The identified shift in age distribution, the vaccination status of reported cases, and serosurveys indicate that inadequate coverage (with less than two mumps vaccine doses) is the main reason for outbreaks und sustained mumps virus circulation in Germany. In 2010, the German Standing Committee on Vaccination (STIKO) recommended an additional MMR vaccination for persons born after 1970 with less than two measles vaccinations in their childhood [18], a recommendation that may simultaneously close some of the existing mumps vaccination gaps in adults. However, no catch-up vaccination activities for mumps have been initiated so far. In view of recent mumps outbreaks among adolescents and young adults and indications of waning immunity, the option of a third routine mumps vaccine dose is being discussed in the scientific literature $[10,14,38]$. However, comprehensive data on the long-term effectiveness of two-dose mumps vaccination (e.g. measured during outbreaks among adolescents and young adults) and on the additional benefits of a third dose are lacking. For the youngest age groups, efforts should focus on sustaining and even increasing the existing high vaccination coverage. In this respect, Finland has set an important example of how to successfully eliminate mumps by reaching and maintaining vaccination coverages of more than $95 \%$ [39].

\section{Acknowledgements}

We thank all Associations of Statutory Health Insurance Physicians for providing claims data; the district and state health authorities of Brandenburg, Mecklenburg-Western Pomerania, Saxony, Saxony-Anhalt, and Thuringia as well as the Bavarian district health authorities for collecting and transmitting mumps case notification data; Marcel Feig for initial preparation of ASHIP data, Kristin Tolksdorf for her statistical support, and Katharina Alpers for her helpful comments on the manuscript draft (all Robert Koch Institute).

The project was funded by the Robert Koch Institute and the German Federal Ministry of Health.

Conflict of interest

None declared.

Authors' contributions

JK, AT and OW developed the design for the study; CK and WH coordinated the collection of the Bavarian surveillance data; TR and AT were involved in ASHIP data management and analyses; AT drafted the manuscript; all co-authors reviewed and assisted in the editing of the final version of the manuscript.

\section{* Erratum:}

The names of C Klinc and J Koch were erroneously left out of the list of authors at the time of publication of this article. This mistake was corrected on 16 August 2013 and we apologise to the authors.

\section{References}

1. Hviid A, Rubin S, Mühlemann K. Mumps. Lancet. 2008;371(9616):932-44.http://dx.doi.org/10.1016/ S0140-6736(08)60419-5

2. Rubin S, Plotkin SA. Mumps vaccine. In: Plotkin SA, Orenstein WA, Offit PA, editors. Vaccines. 6 ed. Philadelphia PA: Saunders; 2013. p.419-46.

3. Levy-Bruhl D, Pebody R, Veldhuijzen I, Valenciano M, Osborne K. ESEN: a comparison of vaccination programmes - Part three: measles mumps and rubella. Euro Surveill. 1998;3(12):pii=112. Available from: http://www.eurosurveillance.org/ViewArticle. aspx?Articleld $=112$

4. Galazka AM, Robertson SE, Kraigher A. Mumps and mumps vaccine: a global review. Bull World Health Organ. 1999;77(1):314. PMid:10063655 PMCid:PMC2557572

5. Savage E, Ramsay M, White J, Beard S, Lawson H, Hunjan $\mathrm{R}$, et al. Mumps outbreaks across England and Wales in 2004: observational study. BMJ. 2005;330(7500):1119-20. http://dx.doi.org/10.1136/bmj.330.7500.1119 PMid:15891227 PMCid:PMC557891

6. Lievano F, Galea SA, Thornton M, Wiedmann RT, Manoff SB, Tran TN, et al. Measles, mumps, and rubella virus vaccine 
(M-M-RII): A review of 32 years of clinical and postmarketing experience. Vaccine. 2012;30(48):6918-26. http://dx.doi. org/10.1016/j.vaccine.2012.08.057 PMid:22959986

7. Cohen C, White JM, Savage EJ, Glynn JR, Choi Y, Andrews N, et al. Vaccine Effectiveness Estimates, 2004-2005 Mumps Outbreak, England. Emerg Infect Dis. 2007;13(1):12-7. PMid:17370510 PMCid:PMC 2913658

8. Park DW, Nam MH, Kim JY, Sohn JW, Cho Y, Song KJ, et al. Mumps outbreak in a highly vaccinated school population: Assessment of secondary vaccine failure using IgG avidity measurements. Vaccine. 2007;25(24):4665-70. http://dx.doi. org/10.1016/j.vaccine.2007.04.013 PMid:17498856

9. Boxall N, Kubínyiová M, Kubínyiová V, Beneš C, Cástková I. An increase in the number of mumps cases in the Czech Republic, 2005-2006. Euro Surveill. 2008;13(16):pii=18842. Available from: http://www.eurosurveillance.org/ViewArticle. aspx?Articleld=18842 PMid:18768117

10. Dayan GH, Quinlisk MP, Parker AA, Barskey AE, Harris ML, Schwartz JM, et al. Recent resurgence of mumps in the United States. New Engl J Med. 2008;358(15):1580-9. http://dx.doi. org/10.1056/NEJMoa0706589 PMid:18403766

11. Schmid D, Holzmann H, Alfery C, Wallenko H, Popow-Kraupp $\mathrm{TH}$, Allerberger F. Mumps outbreak in young adults following a festival in Austria, 2006. Euro Surveill. 2008;13(7):pii=8042. Available from: http://www.eurosurveillance.org/ViewArticle. aspx?Articleld $=8042$

12. Brockhoff HJ, Mollema L, Sonder GJ, Postema CA, van Binnendijk RS, Kohl RH, et al. Mumps outbreak in a highly vaccinated student population, The Netherlands, 2004. Vaccine. 2009;28(17):2932-6. http://dx.doi.org/10.1016/j. vaccine.2010.02.020 PMid:20188683

13. Stein-Zamir C, Shoob H, Abramson N, Tallen-Gozani E, Sokolov I, Zentner G. Mumps outbreak in Jerusalem affecting mainly male adolescents. Euro Surveill. 2009;14(50):pii=19440. Available from: http://www.eurosurveillance.org/ViewArticle. aspx?Articleld=19440 PMid:20070937

14. Anis E, Grotto I, Moerman L, Warshavsky B, Slater PE, Lev B. Mumps outbreak in Israel's highly vaccinated society: are two doses enough? Epidemiol Infect. 2012;140(3):439-46. http:// dx.doi.org/10.1017/S095026881100063X PMid:21554780

15. Barskey AE, Schulte C, Rosen JB, Handschur EF, RauschPhung E, Doll MK, et al. Mumps outbreak in Orthodox Jewish communities in the United States. New Engl J Med. 2012;367(18):1704-13. http://dx.doi.org/10.1056/ NEJMoa1202865 PMid:23113481

16. Robert Koch Institute (RKI). Änderung der Empfehlung zur Impfung gegen Mumps. [Change of the vaccination recommendation against mumps]. EpiBull. 2012;31:3148. German. Available from: https://www.rki.de/DE/ Content/Infekt/EpidBull/Archiv/2012/Ausgaben/31_12. pdf?_blob=publicationFile

17. Robert Koch Institute (RKI). Mumpsausbruch an einer Grundschule in Nürnberg 2011 - Exemplarische Beschreibung des Ausbruchsmanagements und geplante Änderung der STIKO-Empfehlung zur beruflich indizierten Mumpsimpfung. [Mumps outbreak at a primary school in Nuremberg 2011 - exemplary description of the outbreak management and intended changes of the STIKO recommendation regarding occupational mumps vaccination]. EpiBull. 2012;22:20511. German. Available from: https://www.rki.de/DE/ Content/Infekt/EpidBull/Archiv/2012/Ausgaben/22_12. pdf?_blob=publicationFile

18. Robert Koch Institute (RKI). The German Standing Committee on Vaccinations (STIKO). Berlin: RKI. [Accessed 1 Aug 2012]. Available from: http://www.stiko.de/en

19. Robert Koch Institute (RKI). Impfquoten. [Vaccination coverage rates]. Berlin: RKI. [Accessed 21 Nov 2012]. German. Available from: http://www.rki.de/DE/Content/Infekt/Impfen/ Impfstatus/impfstatus_node.html

20. Robert Koch Institute (RKI). Krankheiten, für die gemäß LVO eine erweiterte Meldepflicht zusätzlich zum IfSG besteht (Stand 2009). [Diseases that require extended notification based on legal ordinance by federal states in addition to the German Infection Protection Act (effective: 2009)] EpiBull. 2009;5:33-49. German. Available from: https://www.rki.de/ DE/Content/Infekt/EpidBull/Archiv/2009/Ausgaben/05_09. pdf?_blob=publicationFile

21. German Ministry of Health. Zahlen und Fakten zur Krankenversicherung. Mitglieder und Versicherte. [Numbers and facts regarding health insurance. Members and insured. Berlin: Ministry of Health]. [Accessed 27 July 2012]. German. Available from: http://www.bmg. bund.de/krankenversicherung/zahlen-und-fakten-zurkrankenversicherung.html

22. Statistical offices of the Federation and the Länder. Gebiet und Bevölkerung. [Area and population]. Stuttgart: Statistical offices of the Federation and the Länder. [Accessed 3 Aug 2012]. German. Available from: http://www.statistik-portal.de/ Statistik-Portal/de_jb01_jahrtab1.asp

23. Faensen D, Claus H, Benzler J, Ammon A, Pfoch T, Breuer T, et al.SurvNet@RKI - a multistate electronic reporting system for communicable diseases. Euro Surveill. 2006;11(4):pii=614. Available from: http://www.eurosurveillance.org/ViewArticle. aspx?Articleld=614 PMid:16645245

24. Pöhn HP, Rasch G. Statistik meldepflichtiger übertragbarer Erkrankungen. [Statistic of notifiable infectious diseases ].München: MMV Medizin Verlag; 1994. 219 p. German.

25. Anderson RM, May RM. Immunisation and herd immunity. Lancet. 1990;335 (8690):641-45. http://dx.doi. org/10.1016/0140-6736(90)90420-A

26. Poethko-Muller C, Mankertz A. Seroprevalence of measles-, mumps- and rubella-specific IgG antibodies in German children and adolescents and predictors for seronegativity. PloS one. 2012;7(8):e42867. http://dx.doi.org/10.1371/journal. pone.0042867 PMid:22880124 PMCid:PMC3412821

27. Stehr K, Heininger U. Die Impfsituation in den alten Bundesländern [State of vaccination in the Western federal states]. Dtsch Arztebl. 1991;88(42):1986-91. German.

28. European Centre for Disease Prevention and Control (ECDC). Annual epidemiological report on communicable diseases in Europe 2010. Stockholm: ECDC; 2010. Available from: http:// ecdc.europa.eu/en/publications/publications/1011_sur annual_epidemiological_report_on_communicable_diseases in europe.pdf

29. European Centre for Disease Prevention and Control (ECDC). Annual epidemiological report 2011. Reporting on 2009 surveillance data and 2010 epidemic intelligence data. Stockholm: ECDC; 2011. Available from: http://ecdc. europa.eu/en/publications/Publications/1111_SUR_Annual Epidemiological_Report_on_Communicable_Diseases_in_ Europe.pdf

30. European Centre for Disease Prevention and Control (ECDC). Annual epidemological repot on communicable diseases in Europe 2008. Stockholm: ECDC; 2008. Available from: http:// ecdc.europa.eu/en/publications/publications/0812_sur annual_epidemiological_report_2008.pdf

31. Eriksen J, Davidkin I, Kafatos G, Andrews N, Barbara C, Cohen D, et al. Seroepidemiology of mumps in Europe (1996-2008): why do outbreaks occur in highly vaccinated populations? Epidemiol Infect. 2013;141(3):651-66. http://dx.doi. org/10.1017/So950268812001136 PMid:22687578

32. Morgan C, Adlard N, Carroll S, Parvataneni L. Burden on UK secondary care of rotavirus disease and seasonal infections in children. Current medical research and opinion. 2010;26(10):2449-55. http://dx.doi.org/10.1185/03007995.201 0.518135 PMid:20818925

33. Ariza-Mejia MC, Garcia-Garcia L, Gonzalez-Escalada A, Alvaro-Meca A, Gil-de-Miguel A, Gil-Prieto R. Epidemiology of gonorrhoea-related hospitalisations in Spain between 1997 and 2006. Sexual \& reproductive healthcare: official journal of the Swedish Association of Midwives. 2012;3(2):89-92. http:// dx.doi.org/10.1016/j.srhc.2011.12.001 PMid:22578756

34. Guillen JM, Gil-Prieto R, Alvaro A, Gil A. Burden of adult varicella hospitalizations in Spain (2001-2007). Human vaccines. 2010;6(8):659-63. http://dx.doi.org/10.4161/ hv.6.8.12014 PMid:20523119

35. Ultsch B, Siedler A, Rieck T, Reinhold T, Krause G, Wichmann O. Herpes zoster in Germany: quantifying the burden of disease. BMC Infect Dis. 2011;11:173. http://dx.doi.org/10.1186/14712334-11-173 PMid:21679419 PMCid:PMC3141411

36. Sickbert-Bennett EE, Weber DJ, Poole C, MacDonald PD, Maillard JM. Completeness of communicable disease reporting, North Carolina, USA, 1995-1997 and 2000-2006. Emerg Infect Dis. 2011;17(1):23-9. http://dx.doi.org/10.3201/eid1701.100660 PMid:21192850 PMCid:PMC3204630

37. Boehmer TK, Patnaik JL, Burnite SJ, Ghosh TS, Gershman $\mathrm{K}$, Vogt RL. Use of hospital discharge data to evaluate notifiable disease reporting to Colorado's Electronic Disease Reporting System. Public health reports. 2011;126(1):100-6. PMid:21337935 PMCid:PMC3001805

38. Date AA, Kyaw MH, Rue AM, Klahn J, Obrecht L, Krohn T, et al. Long-term persistence of mumps antibody after receipt of 2 measles-mumps-rubella (MMR) vaccinations and antibody response after a third MMR vaccination among a university population. J Infect Dis. 2008;197(12):1662-8. http://dx.doi. org/10.1086/588197 PMid:18419346

39. Peltola H, Davidkin I, Paunio M, Valle M, Leinikki $P$, Heinonen OP. Mumps and rubella eliminated from Finland. JAMA. 2000;284(20):2643-7. http://dx.doi.org/10.1001/ jama.284.20.2643 PMid:11086376 